\title{
Application of ANFIS for Distance Relay Protection in Transmission Line
}

\author{
Azriyenni*, Mohd Wazir Mustafa** \\ *Faculty of Engineering, Universitas Riau, Indonesia \\ **Faculty of Electrical Engineering, Universiti Teknologi Malaysia, Malaysia
}

\begin{tabular}{l}
\hline \hline Article Info \\
\hline Article history: \\
Received Feb 17, 2015 \\
Revised Aug 9, 2015 \\
Accepted Aug 22, 2015 \\
\hline Keyword: \\
ANFIS \\
Detection \\
Distance Relay \\
Fault \\
Transmission Line \\
\hline
\end{tabular}

\begin{abstract}
The techniques hybrid intelligent was introduced in transmission protection that usage in electric power systems. There was applied ANFIS for distance relay protection particularly for transmission line. If a fault occurs during the transmission line identification caused by unwanted fault thus the power delivery to the consumer becomes not going well. Therefore, it would need to provide an alternative solution to fix this problem. The objective of this paper uses impedance transmission line to determine how long the channel spacing will be protected by distance relay. It has been distance relays when fault occurs in transmission line with the application Sugeno ANFIS. The simulation shows it excellent testing results can be contributed to an alternate algorithm that it has good performance to protecting system in transmission line. This application used by using software Matlab.
\end{abstract}

Copyright (c) 2015 Institute of Advanced Engineering and Science. All rights reserved.

\section{Corresponding Author:}

Azriyenni,

Lecturer at Faculty of Engineering,

Universitas Riau, Indonesia.

Jl. Subrantas Simp. Panam Km. 12.5, Pekanbaru, Indonesia

Email: azriyenni@lecturer.unri.ac.id

\section{INTRODUCTION}

Fault occurs in the transmission line is expected to avoided, utility problems and equipment damage from effect of the arc and so on. These failures are disrupted the reliability operation of the power system. The different researchers to overcome in this problem have suggested many various schemes and algorithms. There are several techniques to detect fault in the transmission system, they are: time domain, frequency domain, and wavelet transform and hybrid intelligent technique. Lin et.al presented a detection of fault inpower system by using Adaptive Probabilistic Neural Network architecture [1-3]. The fault detection by usage Probabilistic Neural Network obtains information from primary and backup protective device to create the training set. Also, Omer et.al presented to use of Artificial Neural Network with backpropagation structure as an alternative method for detecting fault and fault classification in transmission systems [4]. The paper can be classified a few faults in unsymmetrical faults. Meanwhile, Chen \& Aggarwal presented a classification of fault and fault detection scheme is apply from data stream signal into transmission system. The decaying flow signals measured using wavelet to obtain the required frequency [5].

The types of faults are identified by proposed scheme of which is choosing neural network to especially distinguish internal disturbance and external disturbances. It can be used the same pattern in the features by extracted earlier [6], [7]. This paper describes how to design and development the new techniques that can detect and classify the type of error by using a Hybrid Intelligent Techniques. It is also introduced the name of Neural Network and Fuzzy Systems. The fault area location hasbecome a necessary step in the fault location of distribution network [21]. The output line voltages at load terminals are used as the medium for fault detection. A line toground fault is defined as a single connection [22]. These results of study are expected good ability of the method that has been used previously. 
In this paper, The ANFIS is presented by using Fuzzy If-then-rules into Neural Network construction using appropriate learning and reduce the outcome of fault based on the data of the training set. ANFIS offers a technique for the fuzzy modeling to study the output of the data set. It is obtained parameters of the membership functions associated with the fuzzy inference system to treat input or output of data. Single line diagram transmission system is model with a voltage of $150 \mathrm{kV}$ and $117 \mathrm{~km}$ long.

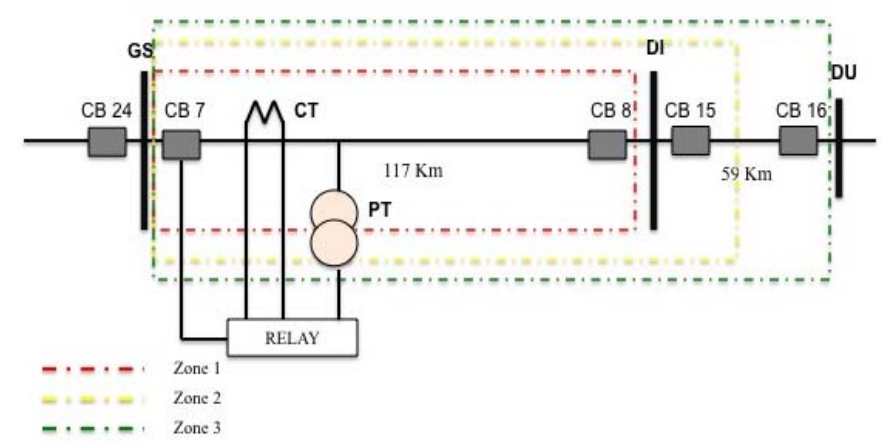

Figure 1. Transmission Line System

$$
\begin{aligned}
& \text { Zone } 1=80 \% *(\mathrm{GS}-\mathrm{DI}) * \mathrm{Z}_{1} * \text { Rasio } \frac{\mathrm{CT}}{\mathrm{PT}} \\
& \text { Zone } 2=\{(\mathrm{GS}-\mathrm{DI})+((\mathrm{DI}-\mathrm{DU}) * 50 \%)\} * \mathrm{Z}_{1} * \text { Rasio } \frac{\mathrm{CT}}{\mathrm{PT}} \\
& \text { Zone } 3=\{(\mathrm{GS}-\mathrm{DI})+(\mathrm{DI}-\mathrm{DU})\} * 120 \% * \mathrm{Z}_{1} * \text { Rasio } \frac{\mathrm{CT}}{\mathrm{PT}}
\end{aligned}
$$

\section{RESEARCH METHOD}

Fuzzy Inference System (FIS) applied with modeling of the systems is not clear. This system has a structure of rules defined by used interpretation features of the model variables. The membership functions are selected in some situations modeling and indistinguishable where the membership function showed it data [3], [6], [10].

ANFIS is a multi-layer method to update network, it is utilized neural network learning algorithms and fuzzy reasoning that are represented input to output. The verbal ability to unify value of a fuzzy system with the numeric value of neural network adaptive, ANFIS has been shown good performance in modeling plenty activity, excellent competence learning and classifying that it could update many systems. It has the advantage of allowing the extraction Fuzzy rules from numerical data or expert knowledge and base adaptively constructs a rule base. In additional, it can be tune difficult conversion of human intelligence to fuzzy Systems [11]-[12], [17]-[20].

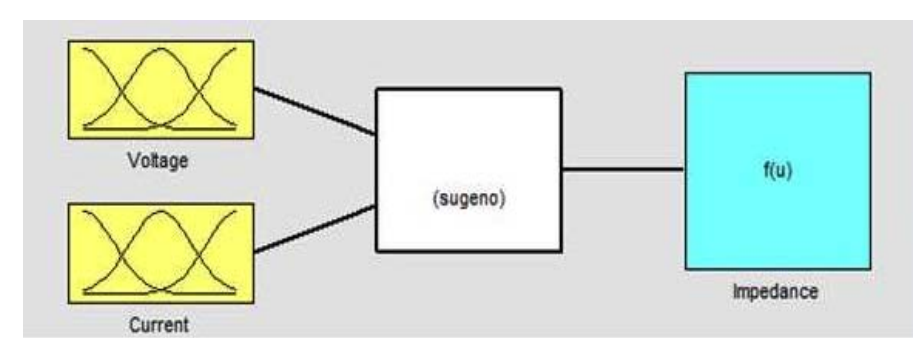

Figure 2. FIS modeling system for voltage and current

Layer 1: Fuzzification

The node of this layer carry out membership degree, which is included to each of compatible fuzzy, sets by using membership functions. 


$$
\begin{aligned}
& \mathrm{O}_{1, \mathrm{i}}=\mu_{\mathrm{A}_{1}}(\mathrm{x}) \text { for } \mathrm{i}=1,2 \\
& \mathrm{O}_{1, \mathrm{i}}=\mu_{\mathrm{B}_{\mathrm{i}-2}}(\mathrm{y}) \text { for } \mathrm{i}=3,4
\end{aligned}
$$

Where: $\mathrm{x}, \mathrm{y}$ are crisp inputs to nodei and $\mathrm{A}_{\mathrm{i}}, \mathrm{B}_{\mathrm{i}}$ are the linguistic labels be coming membership functions $\mu_{A_{i}}, \mu_{B_{i}}$, in every each other.

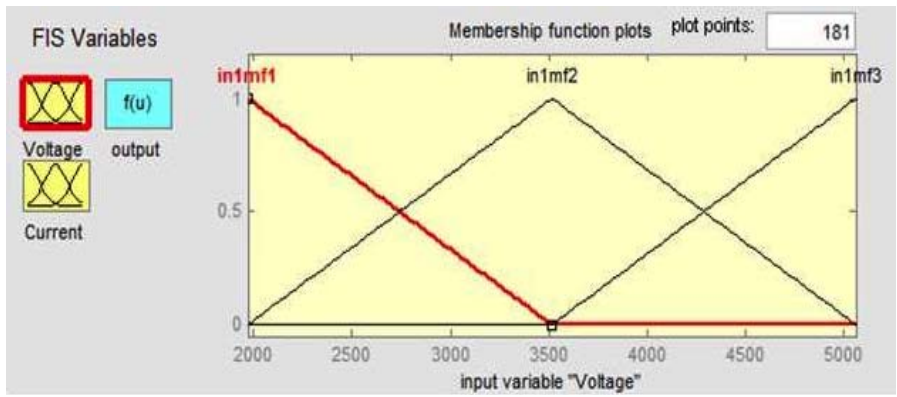

Figure 3. Triangular Membership Function

The membership function can be any appropriate function such as; Gaussian, trapezoidal, generalized bell and triangular [14]. The membership function in this paper shows in Figure 3.

$$
\begin{aligned}
& \mu_{A_{i}}=\left\{\begin{array}{rr}
1-\frac{a_{i 1}-u}{a_{i 2}} \text { if } a_{i 1}-a_{i 2} \leq u \leq a_{i 1} \\
1-\frac{u-a_{i 1}}{a_{i 3}} \text { if } a_{i 1} \leq u \leq a_{i 1}+a_{i 3} \\
0 & \text { otherwise }
\end{array}\right. \\
& \mu_{B_{i}}=\left\{\begin{array}{l}
1-\frac{b_{i 1}-v}{b_{i 2}} \text { if } b_{i 2}-b_{i 2} \leq v \leq b_{i 1} \\
1-\frac{v-b_{i 1}}{b_{i 3}} \text { if } b_{i 1} \leq v \leq b_{i 1}+b_{i 3} \\
0 \quad \text { otherwise }
\end{array}\right.
\end{aligned}
$$

Where: $\left\{a_{i}, b_{i}, c_{i}\right\}$ are parameter set of the membership functions in premise part of fuzzy if-then rules that changes the shapes of the membership function.

Layer 2: If-Then rule

The AND operator used up to one output which indicates the result of the antecedent for rule, i.e., firing strength. Firing strength means is the degree antecedent part of a fuzzy rule, which satisfied, and it shapes output function for the rule. In the other hand, the outputs $\mathrm{O}_{2, \mathrm{k}}$, of this layer are products of appropriate degrees.

$$
\begin{aligned}
& \mathrm{O}_{2, \mathrm{k}}=\mathrm{w}_{\mathrm{k}}=\mu_{\mathrm{A}_{\mathrm{i}}}(\mathrm{x}) * \mu_{\mathrm{B}_{\mathrm{i}}}(\mathrm{y}) \\
& \mathrm{i}=1,2 ; \quad \mathrm{j}=1,2 ; \mathrm{k}=2(\mathrm{i}-1)+\mathrm{j}
\end{aligned}
$$

Layer 3: Normalization

The main objective is to manage numerate the ratio of each rule's firing strength to the sum of all rules firing strength. In every each special chase, $\overline{\mathrm{w}_{1}}$ is taken as the normalize strength.

$$
\mathrm{O}_{3, \mathrm{i}}=\overline{\mathrm{w}_{1}}=\frac{\mathrm{w}_{\mathrm{i}}}{\mathrm{w}_{1}+\mathrm{w}_{2}+\mathrm{w}_{3}+\mathrm{w}_{4}} \quad \mathrm{i}=1,2,3,4
$$

Layer 4: Defuzzification

The node function of the fourth layer count up the effect of each rule toward the total output and establish it as follow:

$$
\mathrm{O}_{3, \mathrm{i}}=\overline{\mathrm{w}_{1}} \mathrm{z}_{\mathrm{i}}=\overline{\mathrm{w}_{1}}\left(\mathrm{p}_{\mathrm{i}} \mathrm{x}+\mathrm{q}_{\mathrm{i}} \mathrm{y}+\mathrm{r}_{\mathrm{i}}\right) \quad \mathrm{i}=1, \ldots, 4
$$


Layer 5: Neuron Addition

The node calculates all of the output by summing all the incoming signals. In consequence, the defuzzification create process each rule's fuzzy results into a crisp output in this layer.

$$
\mathrm{O}_{5,1}=\sum_{\mathrm{i}=1}^{4} \overline{\mathrm{w}}_{\mathrm{i}} \mathrm{z}_{\mathrm{i}}=\frac{\mathrm{w}_{1} \mathrm{z}_{1}+\mathrm{w}_{2} \mathrm{z}_{2}+\mathrm{w}_{3} \mathrm{z}_{3}+\mathrm{w}_{4} \mathrm{z}_{4}}{\mathrm{w}_{1}+\mathrm{w}_{2}+\mathrm{w}_{3}+\mathrm{w}_{4}}
$$

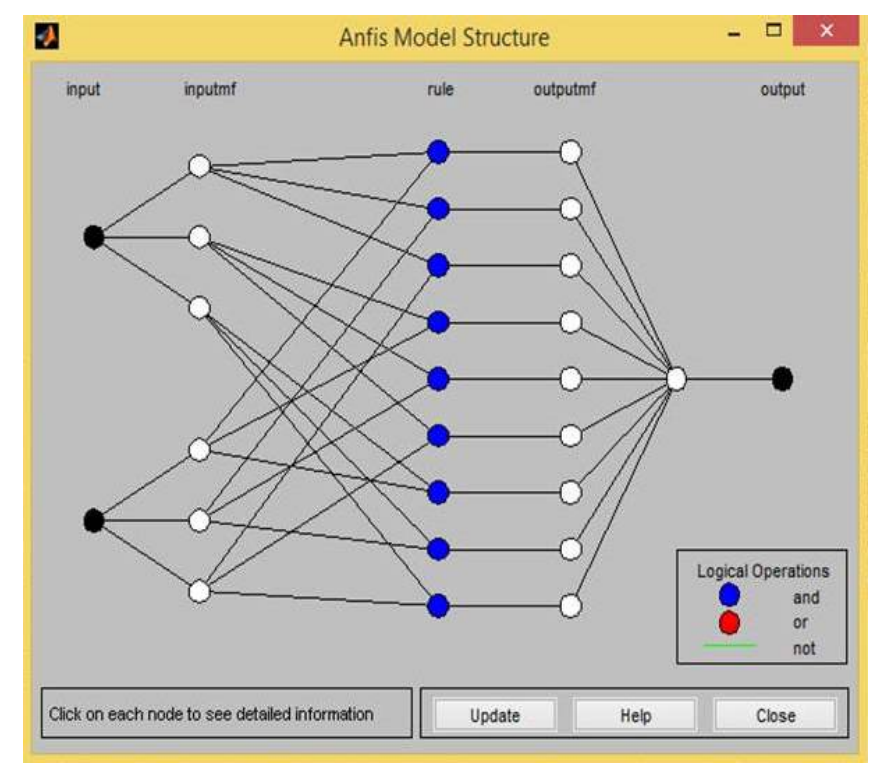

Figure 4. Structure of ANFIS Model

The structure of ANFIS is showed in Figure 4, in which a circle shows a it to fixed node while a square adduces an adaptive node [15]. Toward easiness, the fuzzy inference system contemplation has two inputs, $\mathrm{x}$ and $\mathrm{y}$ and one output $\mathrm{z}$. This network is trained concern of observe learning. The purpose train adaptive networks to provide unknown functions with appointed training data and calculate the result obtain of the value above parameters. The different of typical of the approach ANFIS have a hybrid algorithm, the gradient descent method and the least-squares method, to update parameters. The gradient descent classification is used to tune premise non-linear parameters $\left(\left\{i_{a}, i_{b}, i_{c}\right\}\right)$, At the time, least squares technique utilize to recognize consequent linear parameters $\left(\left\{\mathrm{i}_{\mathrm{p}}, \mathrm{i}_{\mathrm{q}}, \mathrm{i}_{\mathrm{r}}\right\}\right)$. Thus, the fault comes to through signals propagate backward. Gradient descent takes a new technique the premise parameters. When the process consequent parameters improve can be reduce the overall quadratic operational cost. The analyzing and mathematical observe condition of the hybrid-learning algorithm will show it in [14], [15].

\section{RESULTS AND ANALYSIS}

The application of the adaptive techniques will determine zone setting of distance relay protecting the transmission system illustrated in Figure 1. The test system consists of 24 distance relays operating at 150 $\mathrm{kV}$ levels. The power system analyzed are setting and checking to coverage provided by each zone of distance relay.

Figure 5 shows the impedance data at any distance from the substation to the next substation. Training of this model may optimize parameter as a training error. The variation of the training error is respect to the number of iteration for this model. The variation of impedance with different zone input is shown in Figure 8 and 9. 

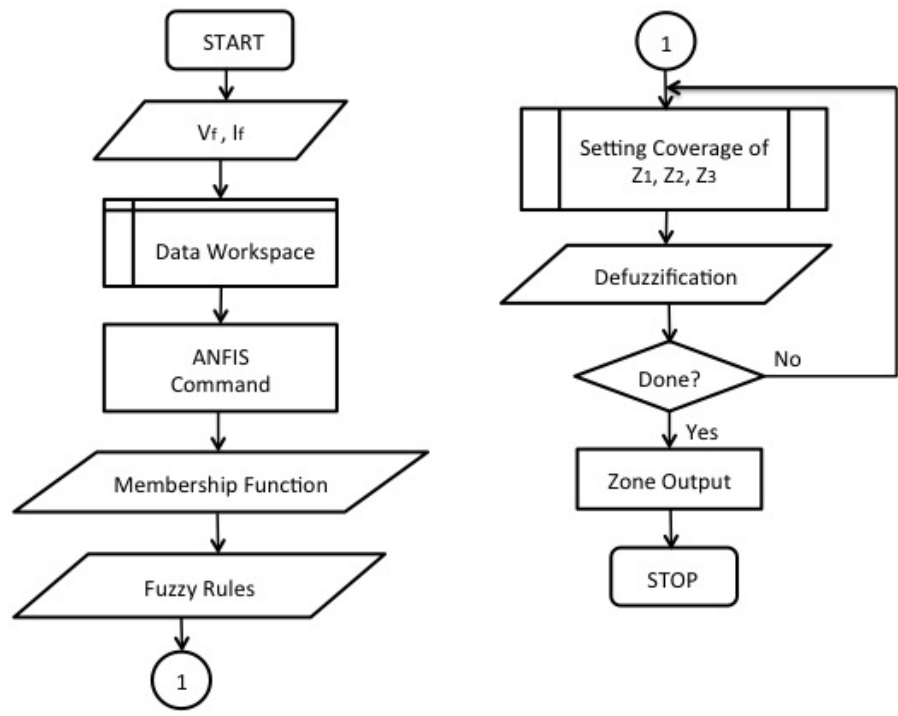

Figure 5. Flowchart Sugeno ANFIS

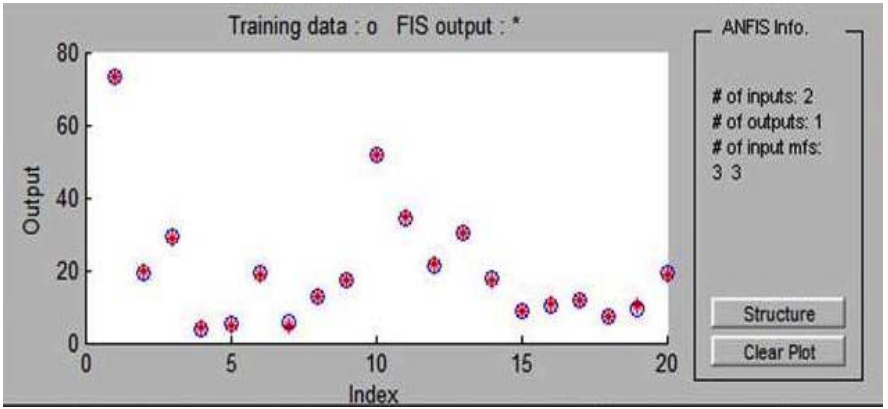

Figure 6. Training of Data with epochs for $\mathrm{f}(\mathrm{u})$

There are 9 rules, which are sufficient to identify coverage zone using ANFIS. Some of these rules are as follows:

1) If (voltage is in $1 \mathrm{mfl}$ ) and (current is in $2 \mathrm{mfl}$ ) then (impedance is out $1 \mathrm{mfl})$ (1)

2) If (voltage is in $1 \mathrm{mf} 1$ ) and (current is in $2 \mathrm{mf} 2$ ) then (impedance is out1 $\mathrm{mf} 2$ ) (1)

3) If (voltage is in $1 \mathrm{mf} 3$ ) and (current is in $2 \mathrm{mf} 3$ ) then (impedance is out $1 \mathrm{mf} 3$ ) (1)

4) If (voltage is in $1 \mathrm{mf} 2$ ) and (current is in $2 \mathrm{mf1}$ ) then (impedance is out $1 \mathrm{mf} 4)$ (1)

5) If (voltage is in $1 \mathrm{mf} 2$ ) and (current is in $2 \mathrm{mf} 2$ ) then (impedance is out $1 \mathrm{mf} 5)$ (1)

6) If (voltage is in $1 \mathrm{mf} 3$ ) and (current is in $2 \mathrm{mf} 3$ ) then (impedance is out1 mf6) (1)

7) If (voltage is in $1 \mathrm{mf} 3$ ) and (current is in $2 \mathrm{mf} 1$ ) then (impedance is out $1 \mathrm{mf} 7)$ (1)

8) If (voltage is in $1 \mathrm{mf} 3$ ) and (current is in $2 \mathrm{mf} 2$ ) then (impedance is out $1 \mathrm{mf} 8$ ) (1)

9) If (voltage is in $1 \mathrm{mf} 3$ ) and (current is in $2 \mathrm{mf} 3$ ) then (impedance is out $1 \mathrm{mf} 9$ ) (1)

The system simulation MATLAB results are shown in Figure 6 until Figure 10. The input entered to the ANFIS then voltage and current are testing data for the training process. All values obtained from the corresponding fault where given as input for the ANFIS and also will be got better results with the values as supposed. The based rules ANFIS used to optimize training modeledwhich is shown in Figure 8 until 10. The technique proposed uses short circuit fault to determine the apparent impedance seen by zone relay protection. When the faults are giving rise to far from buses and fault are including current effect to corresponding zone coverage. The required zone reaches are computed for all network topologies that is considering contingencies and outputs of generation source. 

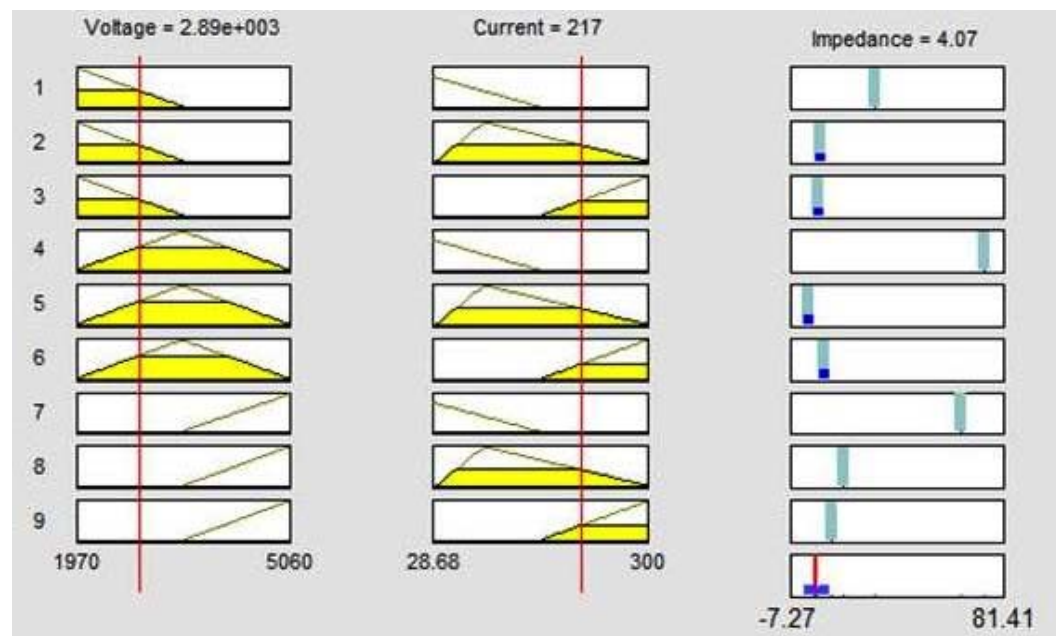

Figure 7. Defuzzification for setting of zone protection

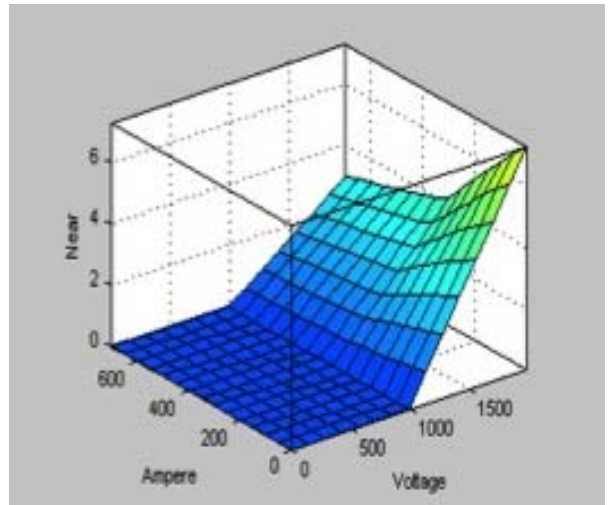

Figure 8. Relation current and voltage to main zone coverage

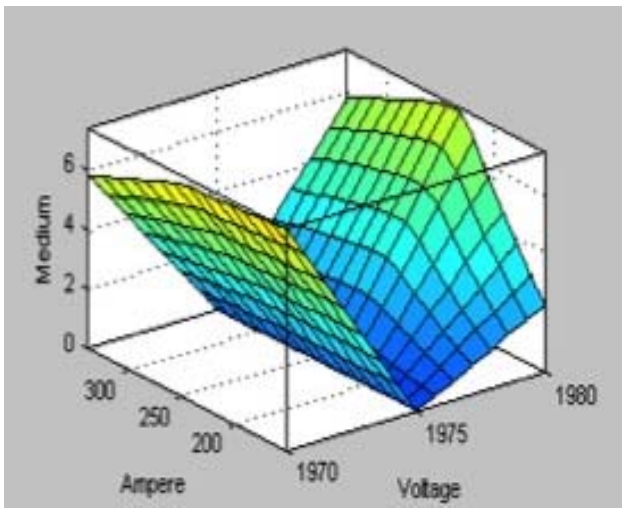

Figure 9. Relation current and voltage to the first backup zone coverage

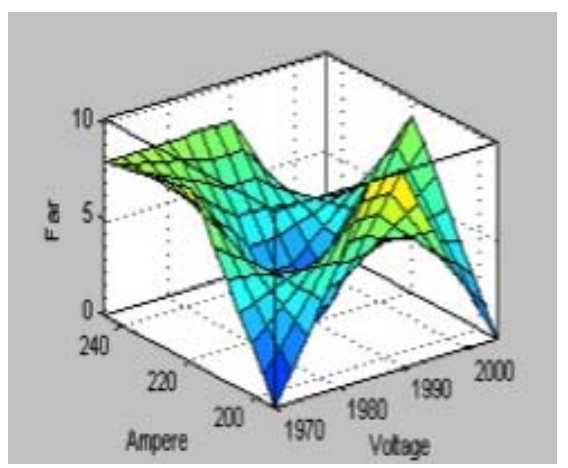

Figure 10. Relation current and voltage to the second backup zone coverage

From the Table 1, it can conclude that ANFIS model is superior to ANN [3] in amount of adjusted parameters, scale of training data, and testing error. Training error satisfies the requirements. It is clear that ANFIS is more effective subject to small scale sample data. 
Table 1. Comparison of the proposed ANFIS and ANN

\begin{tabular}{lcc} 
& \multicolumn{2}{c}{ METHOD } \\
& ANN & ANFIS \\
\hline Input Layer & 20 & 2 \\
Hidden/Rules & 3 & 9 \\
Output Layer & 24 & 1 \\
Error of Testing & 0.001 & 0 \\
Training & 48,370 & 3,000 \\
\hline
\end{tabular}

\section{CONCLUSION}

ANFIS has served in this paper integrated by using Neural Network with Fuzzy Inference System. Where Fuzzy system serves as the Fuzzy Inference System. The proposed ANFIS is a new scheme to determine setting of zone distance relays. The zone of a distance protection scheme was recognized one of contributing causes of blackouts. Therefore, determining the accurate zone setting of distance relay is considered necessary. The backup protection can be coverage by using proposed technique in comparison with the conventional technique. The approach scheme can be used in normal condition and during on processfailures. Lastly, test results can help one of the intelligent alternative techniques that have very good performance to improve the transmission line.

\section{REFERENCES}

[1] Lin W. M, et al., "Adaptive multiple fault detection and alarm processing for loop system with probabilistic network," IEEE Transactions on Power Delivery, Vol. 19, No. 1, pp. 64-69, 2004.

[2] Souza J. C. S, et al., "Fault Location in Electrical Power Systems Using Intelligent Systems Techniques," IEEE Transactions on Power Delivery, Vol. 16, No. 1, pp. 59-67, 2001.

[3] Azriyenni, et al., "Application of Backpropagation Neural Network for Fault Location in Transmission Line 150 kV," IJEEE, Vol. 2, No. 4, pp. 21-30, 2013.

[4] Omer E. B. M. T, "Transmission Line Faults Detection, Classification and Location using Artificial Neural Network," IEEE, pp. 1-5, 2012.

[5] Chen J, and Aggarwal R. K, "A New Approach to EHV Transmission Line Fault Classification and Fault Detection Based on the Wavelet Transform and Artificial Intelligence," IEEE, pp. 1-8, 2012.

[6] Yu W, and Li X, "Fuzzy identification using fuzzy neural networks with stable learning algorithms," IEEE Transaction on Fuzzy System, Vol. 12, No. 3, pp. 411-419, 2004.

[7] Negnevitsky M, and Pavlovsky V, "Neural Network Approach to Online Identification of Multiple Failures of Protection Systems," IEEE Transactions on Power Delivery, Vol. 20, No. 2, pp. 588-594, 2005.

[8] Zhang J. F, et al., "Morphological Undecimated Wavelet Decomposition for Fault Location On Power Transmission Lines," IEEE Transactions on Circuits and Systems, Vol. 53, No. 6, pp. 1395-1402, 2006.

[9] Zang H, and Zhao Y, "Intelligent Identification System of Power Quality Disturbance in Global Congrress Systems," IEEE Computer Society, pp. 258-261, 2009.

[10] Yusuff A. A, et al., "A Novel Fault Features Extraction Scheme for Power Transmission Line Fault Diagnosis," IEEE Africon, pp. 1-4, 2011.

[11] Shirazi S, et al., "Prediction of Failure in Pin-Joint Using Hybrid Adaptive Neuro-Fuzzy Approach," IEEE International Conference on Fuzzy Systems, pp. 671-677, 2006.

[12] Nayak C, et al., "Prediction of Cutting and Feed Forces for Conventional Milling Process using Adaptive Neuro Fuzzy Inference System (ANFIS)," IAES International Journal of Artificial Intelligence (IJ-AI), Vol. 3, No. 1, pp. 24-35, 2011.

[13] Zhang M, “An On-Line Arterial Route Travel Time Prediction Application Using ANFIS”, IEEE, pp. 1-4, 2009.

[14] Bahramifar A, et al., "An ANFIS-based approach for Predicting the Manning Roughness Coefficient in Alluvial Chanels at the Bank-Full Stage," IJE Transactions B: Application, Vol. 26, No. 2, pp. 177-186, 2013.

[15] Sarikaya N, et al., "Adaptive Neuro-Fuzzy Inference System For The Computating of The Characteristic Impedance and Effective Permittivity of The Micro-Coplanar Strip Line," Electromagnetics Research, pp. 225-237, 2008.

[16] Silva, A. P. A, et al., "Neural Networks for Fault Location in Substations", IEEE Transactions on Power Delivery, Vol. 11, No. 1, 1996.

[17] Dash P. K, et al., “A Novel Fuzzy Neural Network Based Distance Relaying Scheme,” IEEE Transactions on Power Delivery, Vol. 15, No. 3, pp. 902-907, 2000.

[18] Anis Ibrahim W. R, et al., "An Adaptive Fuzzy Self-Learning Technique for Prediction of Abnormal Operation of Abnormal Operation of Electrical Systems", IEEE Transactions on Power Delivery, Vol. 21, No. 4, pp. 1770-1777, 2006.

[19] Buckley J. J, Hayashi Y, “Neural Nets for Fuzzy Systems," Fuzzy Sets and Systems, Vol. 71, pp. 265-276, 1995.

[20] Nauck D, Kruse R, “A Neuro-Fuzzy Method to Learn Fuzzy Classification Rules from Data," Fuzzy Sets and Systems, Vol. 89, pp. 277-288, 1997. 
[21] Zhongjian K, Aina T, Zhe B, “A Fault Area Location Method in Distribution Network With DG,” Telkomnika, Vol. 11, no. 11, pp. 6870-6878, 2013.

[22] Sheelavant V. R, Vijaya C, Shiralashetti S. C, "Wavelet Based Fault Detection Method for Ungrounded Power System with Balanced and Unbalanced Load," IJECE, Vol. 1, No. 1, pp. 2088-8708, 2011.

\section{BIOGRAPHIES OF AUTHORS}

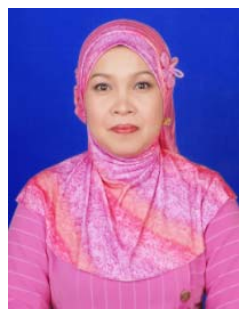

Azriyenni received the Bachelor degree from Universitas BungHatta, Padang, Indonesia, in 1998 and the Master Degree form Universiti Teknologi Malaysia, Johor Bahru, in 2007. Now, She is doing Ph.D in Universiti Teknologi Malaysia, All in Electrical Engineering. Since 1999, She was Lecturer in Department Electrical, Universitas of Riau, Pekanbaru, Indonesia. Her research interests include Power System Protection, Transmission \& Distribution Systems and Artificial Intelligence.

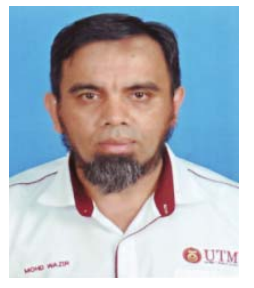

M.W Mustafa received his B.Eng degree (1988), M.Sc (1993) and Ph.D (1997) from University of Strathclyde, Glasgow. He is a Professor in Faculty of Electrical Engineering, UTM. He is also currently Deputy Dean (Academic) in Faculty of Electrical Engineering, Universiti Teknologi Malaysia. His research interest includes Power System Stability, Deregulated Power System, FACTS, Power Quality, Power System Distribution Automation and Artificial Intelligence. 